\title{
Nunavut extends implementation of suicide prevention plan
}

I $\mathrm{n}$ the wake of a record number of suicides in 2013, Nunavut has agreed to a one-year extension of an action plan to implement the territory's suicide prevention strategy.

"Greater effort is needed to combat the rate of suicide that stands before us," the Commissioner of Nunavut, Edna Elias, said in the Legislative Assembly's Speech from the Throne on Mar. 20.

Last year, 45 Inuit committed suicide in Nunavut, the highest number of suicides recorded since the territory was created in 1999. That number corresponds to a suicide rate of 156 deaths per 100000 people - 13.5 times the most recently available national rate (2009) of 11.5 per 100000.

Nunavut Deputy Premier Minister of Health Monica Ell tacitly acknowledges that the government has not been able to fully implement the Nunavut Suicide Prevention Strategy Action Plan, which was set to expire Mar. 31. However, she insists that "a lot of progress has been made" on the plan's eight overarching commitments.

The Embrace Life Council, a partner in the prevention strategy, had called for a five-year extension to the action plan earlier this year. Embrace Life Council President Sandra Kownak now says the one-year extension will allow the partners to evaluate how each organization has fulfilled its responsibilities for the 41 actions associated with the plan's overall commitments.

"From there we can gauge how much more time we need to deliver on those results," Kownak told CMAJ.

Launched Sept. 11, 2011, the plan's prevention strategies were designed to be implemented over two-and-a-half years as an urgent response to the high numbers of completed and attempted suicides by Inuit. No budget, however, was ever attached to the strategy.

Among other actions, the plan calls for the Government of Nunavut to:

- hire additional mental health professionals;

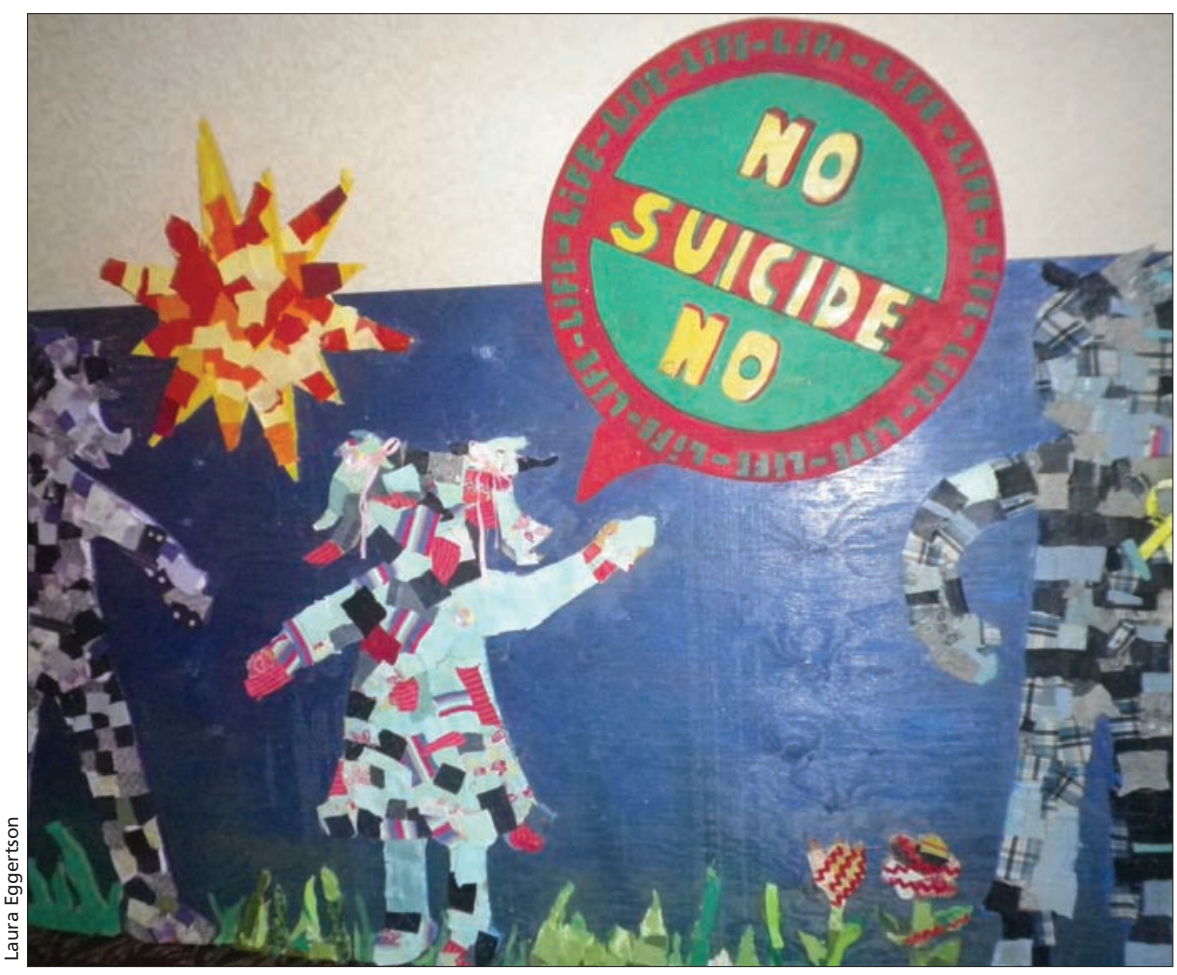

Last year, 45 Inuit committed suicide in Nunavut, which corresponds to a rate of 156 deaths per 100000 population.

- create an integrated mental health strategy;

- construct or acquire additional mental health and addiction facilities;

- identify and implement programs to reduce physical and sexual abuse of children;

- support children and youth demonstrating at risk-behaviours;

- offer widespread training in a suicide prevention program; and,

- conduct awareness and education campaigns aimed at reducing risk factors.

The number of suicides in 2013 prompted Nunavut's Chief Coroner Padma Suramala to call for a review of the deaths, which is expected to focus on the reasons Nunnavummiut are killing themselves and on what preventive measures are still lacking.

Already this year, there have been at least seven suicides in Nunavut, includ- ing a man in his 20s whose father also committed suicide.

Cape Dorset's Member of the Legislative Assembly, David Joanasie, questioned whether the territory's new government, which took office last October, remains committed to suicide prevention.

"Too many Nunavummiut appear to be losing hope," Joanasie told the Assembly. "Can the Minister [of Health] confirm whether this strategy is still a priority for this government or has it been abandoned?"

Ell insists the territorial government is continuing to work on implementing the action plan, along with Embrace Life, the Royal Canadian Mounted Police and Nunavut Tunngavik Incorporated, its other partners in the suicide prevention strategy. - Laura Eggertson, Ottawa, Ont.

CMAJ 2014. DOI:10.1503/cmaj.109-4770 